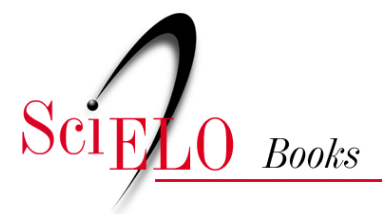

\title{
EDUFU
}

\section{O pedagogo prático e seu método em perene construção \\ J. H. Pestalozzi (1746-1827)}

Bruno Bontempi Jr.

\section{SciELO Books / SciELO Livros / SciELO Libros}

BONTEMPI JR., B. O pedagogo prático e seu método em perene construção: J. H. Pestalozzi (1746-1827). In: BOTO, C., ed. Clássicos do pensamento pedagógico: olhares entrecruzados [online]. Uberlândia: EDUFU, 2019, pp. 71-87. História, Pensamento, Educação collection. Novas Investigações series, vol. 9. ISBN: 978-65-5824-027-3. Available from:

http://books.scielo.org/id/fjnhs/pdf/boto-9786558240273-05.pdf. https://doi.org/10.14393/edufu-978-85-7078-472-8.

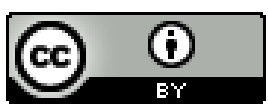

All the contents of this work, except where otherwise noted, is licensed under a Creative Commons Attribution 4.0 International license.

Todo o conteúdo deste trabalho, exceto quando houver ressalva, é publicado sob a licença Creative Commons Atribição 4.0.

Todo el contenido de esta obra, excepto donde se indique lo contrario, está bajo licencia de la licencia Creative Commons Reconocimento 4.0. 


\section{O pedagogo prático e seu método em perene construção: J. H. Pestalozzi (1746-1827)}

Bruno Bontempi Jr.

\section{Introdução}

A tentativa de organizar o "pensamento educacional" de Pestalozzi é um bom exercício e também uma lição para o historiador das ideias: o pensamento é vivo e dinâmico, em movimento consoante não apenas com a reflexão teórica, mas com as vicissitudes da experiência. Para entendê-lo, é pouco frutífero procurar a coerência entre as ideias de toda a sua produção, ou dela retirar apenas o que os educadores mais tarde valorizariam como sendo correto e útil. Seus acertos, bem como seus erros, suas certezas e suas dúvidas são pontos de um pensamento em movimento e nos obrigam a considerar cada "fase" entendida à luz de sua história de vida e de seu trabalho pedagógico como única e também como parte da metamorfose permanente que os exercícios de reflexão e autocrítica operaram em sua prática de educador. Pestalozzi, à diferença de muitos pensadores que esconderam suas incertezas e contradições, nos permite compreender o "pensamento pedagógico" não como um artefato teórico previamente elaborado para orientar a ação, mas como um imiscuir constante da "teoria" e da "prática", parelha que apenas de modo analítico conseguimos separar. 
Sua grande fragilidade continua sendo o fato de que jamais conseguiu separar verdadeiramente sua obra de si mesmo, de sua existência e de suas experiências. Mas esta fraqueza se transforma em uma força devido a que Pestalozzi nunca deixou de buscar desde o começo: a realização da liberdade autônoma em cada um e em todos. (Söetard, 2010, p. 30).

Em concordância com Söetard (2010), optei por apresentar conjuntamente a vida e o pensamento pedagógico de Pestalozzi, sem separar analiticamente um de outro. Nisso não há originalidade, pois, como afirma Dora Incontri (1996, p. 12), que visitou exaustivamente a vasta produção a respeito do autor, "não existe uma só interpretação sobre esse autor que não tenha largas conexões biográficas”. Afinal, o modo principal pelo qual Pestalozzi nos permitiu aceder a seu pensamento, por cartas, estimula a quem discorre sobre a vida e as ideias do autor a "misturar" as duas coisas e, de certo modo, a restaurar o "processo real" de atividade e reflexão, que se sustenta tanto no saber dos livros como no da experiência vivida. Este ensaio não é uma exposição exaustiva da obra pedagógica de Pestalozzi, tampouco intenta apresentar um ponto de vista inovador para sua análise ${ }^{1}$. Tratase de revelar um autor e sua obra em linhas fundamentais, a fim de promover a familiarização do leitor com as alusões, experiências e reflexões de um pedagogo que se tornou uma referência tanto para a sua época quanto para os nossos dias.

${ }^{1} \mathrm{O}$ leitor brasileiro tem a possibilidade de confrontar análises antitéticas a respeito de Pestalozzi: as interpretações de Incontri (1996) e Arce (2002). Ainda que Arce não tenha enfrentado o diálogo com Incontri, é evidente que os pressupostos de cada uma as levam a conclusões discordantes sobre as motivações e os significados da obra do pedagogo suíço. Assim, enquanto Incontri (1996, p. 23) se recusa a "interpretar as questões levantadas por Pestalozzi como meros reflexos da situação socioeconômica de seu tempo", posto que postula a existência de "verdades que antecedem o tempo histórico", Arce (2002, p. 10) aborda, no outro extremo, o pensamento do autor como "reflexo, no campo educacional, daquele lado ideológico reacionário do pensamento liberal burguês" e "berço ideológico das estratégias de esvaziamento da escola por meio da defesa de uma pedagogia antiescolar". 


\section{Pestalozzi, vida e obra}

Johann Heinrich Pestalozzi nasceu em Zurich, Suíça, em 12 de janeiro de 1746, e faleceu em Brugg, em 17 de fevereiro de 1827. Era filho de uma família italiana de classe média, que empobreceu com a morte do patriarca, médico de profissão. Cursou a escola pública elementar, o ginásio e frequentou, sem concluir, o Colégio Carolino. De acordo com Söetard (2002, p. 13), o jovem Pestalozzi cultivou intensos vínculos com os "pietistas" de Zurich, movimento reformista que se baseia na doutrina da predestinação e que dá ênfase à ascese e à prática da piedade, deixando a doutrina em segundo plano (Weber, 1996, p. 90-91). Não seguiu, entretanto, as carreiras de sacerdote, tampouco a de jurista, inicialmente pretendidas, tendo decidido ser agricultor. Também na juventude, tornou-se "patriota", ou seja, membro da Sociedade Helvética, juntando-se aos que criticavam a situação política do país, clamando por reformas (Incontri, 1996, p. 8). Nessa época,já se encontrava bastante impactado pelas ideias pedagógicas e morais de J. J. Rousseau (1712-1778), particularmente por Emílio (1762), que viria a ser o seu livro de cabeceira. Tanto é verdade que, em 1774, escreveu Diário de um pai, pretendendo relatar os progressos de sua experiência de aplicação dos princípios rosseaunianos à educação de Hans Jakob, filho de seu casamento com Anna Schulthess. Na mesma esteira, Incontri (1996, p. 30) compreende a escolha precoce de Pestalozzi por se estabelecer no campo e ser agricultor como manifestação da busca dos ideais rousseaunianos de volta à natureza.

Motivado pela ideia de regenerar a sociedade mediante a regeneração do homem, no início da década de 1770, Pestalozzi criou uma comunidade-escola em um sítio, que batizou de Neuhof, para educar crianças pobres. O objetivo de Pestalozzi era ainda inspirado em Rousseau (1999, p. 11-13), de reunir no mesmo projeto a educação do homem livre e do cidadão útil, ou seja, promover "a realização 'da dignidade interior mais pura do homem' [...] e 'sua boa formação para as necessidades essenciais de sua vida terrestre”' (Söetard,2010, p.18). Ele 
esperava poder ensinar às crianças educação moral e primeiras letras, associadas ao aprendizado do trabalho na agricultura e no artesanato, mas esbarrou tanto em sua incompetência gerencial como no próprio comportamento das crianças e de suas famílias, que contraditavam sua expectativa de mútua compaixão e esforço para o bem comum. A iniciativa, que se pretendia economicamente autossustentável, fracassou e foi encerrada em 1780, indicando, de acordo com Söetard (2010, p. 17),

uma ingênua confiança no milagre da indústria e, também, na capacidade do homem para dominá-la espontaneamente; uma crença profunda em uma liberdade natural dos filhos de Deus e na virtude de uma educação que se limitaria a acompanhar o movimento da natureza.

Ainda no ano de 1780, impelido pela necessidade de sobrevivência a tornar-se escritor (Incontri, 1996, p. 33), publicou Crepúsculos de um eremita, em que se apresenta intrigado com as causas da miséria e parte em busca da verdadeira essência do homem, preocupação central de toda a sua reflexão e prática pedagógica (Incontri, 1996, p. 33). Ele defende, nessa obra, que o problema de toda a educação é o desenvolvimento das forças interiores da natureza humana. No ano seguinte, publicou o primeiro volume de seu livro mais popular, Leonardo e Gertrudes (2a parte em 1783; $3^{\mathrm{a}}$ em 1785; 4 ${ }^{\mathrm{a}}$ em 1787), apontando o papel decisivo das mães e do lar no desenvolvimento da infância. Trata-se de uma novela pedagógica cuja personagem principal é Gertrudes, mulher que, embora ignorante, introduz, por sua inteligência e devotamento, significativas modificações, tanto no modo de vida de sua família como no de toda a aldeia. No último volume da obra, o papel central fica com Glüphi, militar aposentado que se torna professor de escola elementar e, estendendo à instituição as diretrizes do lar de Gertrudes, também encarna as ideias de Pestalozzi sobre a função da escola e o sentido da educação: o verbalismo é pernicioso, e são as ações que instruem um homem livre e ativo na melhora da sociedade. 
Em 1798, Pestalozzi foi designado para cuidar das crianças órfãs de Stanz, cidade que havia sido queimada pelo exército francês nas batalhas da Revolução Suíça. De acordo com Alessandra Arce (2002, p. 65), nessa escola as práticas eram baseadas nas relações de afeto entre mestre e alunos, as decisões eram tomadas de comum acordo com as crianças e a aprendizagem era baseada em brincadeiras e na experiência cotidiana. Em suas cartas, Pestalozzi relata que, tendo se deparado aos 53 anos de vida com o desafio de educar sozinho dezenas de alunos de diferentes idades, ignorantes e carentes de tudo, teve de aprender "a arte de ensinar a muitos". Não encontrou melhor meio do que falar-lhes em voz alta, tendo chegado "naturalmente" ao recurso de apoiar os mais capazes, assim como à ideia de fazê-los desenhar, escrever e trabalhar durante a aula. Segundo ele, as dificuldades dos alunos o levaram a permanecer mais tempo no que era elementar ou inicial, e assim a experimentar com eles os sentimentos de "plenitude e perfeição, mesmo nos graus mais inferiores”, contrapostos aos “vazios imensos que deviam nascer da confusão e inconclusão desses pontos em cada série de conhecimentos" (Pestalozzi, s/d., p. 29-30)². Ele relata que as experiências de Stanz foram decisivas para reforçar sua crença de que poderia "assentar a instrução do povo sobre fundamentos psicológicos, de colocar como sua base conhecimentos intuitivos reais e de arrancar do ensino a máscara de sua retórica superficial”.

Conheci com eles [...] a relação natural em que hão de achar-se os conhecimentos reais com os conhecimentos verbais; conheci com eles o dano que podem causar à força real da intuição e à consciência firme dos objetos que nos rodeiam o conhecimento parcial das letras e a confiança ilimitada nas palavras quando estas não são senão vozes e sons. (Pestalozzi, s/d., p. 31-32).

Pestalozzi, porém, não permaneceu por muito tempo em Stanz, pois, já em 1799, o exército francês ocupou a escola e determinou

${ }^{2}$ Tradução livre da edição espanhola citada, assim como todas as que se seguem. 
que ele saísse de lá (Arce, 2002, p. 65). Afirma Incontri (1996, p. 25) que Stanz teria sido um "divisor de águas" na vida do autor, pois foi a partir de então que ele passou a se dedicar inteiramente à educação. Crendo que a maior recompensa por seu trabalho na escola havia sido o seu próprio crescimento (Pestalozzi, s/d., p. 34), o pedagogo encontrou meios de continuá-lo, agora como mestre-escola designado pelo governador de Burgdorf. Ele relata, em sua correspondência, que fora recebido nessa cidade com simpatia, mas com certa incredulidade, posto que a presença de sua escola parecia ameaçar as lições dominicais baseadas no Catecismo de Heidelberg (1563), pelo qual, mediante leitura, memória e cópia, tradicionalmente se dava o ensino das classes inferiores nas cidades protestantes da Suíça. Chegou-se a espalhar que Pestalozzi não sabia ler, escrever e contar perfeitamente, mas, surpreendentemente, ele não o nega e assim se justifica:

Podia ensinar a escrever sem sabê-lo corretamente; e, com efeito, minha incapacidade nestas matérias era substancialmente necessária para submergir-se na maior simplicidade do método de ensino e para encontrar os meios com os quais pudesse chegar a ensinar a seus filhos o mais inexperto e o mais ignorante dos homens. (Pestalozzi, s/d., p. 36).

Em Burgdorf, contando agora com colaboradores, adquire paulatinamente a ideia de elaborar "um $\mathrm{ABC}$ da intuição", organizando esse método de alfabetização "segundo as regras físico-mecânicas pelas quais recebemos e conservamos mais facilmente todas as impressões exteriores"(Pestalozzi, s/d., p. 38).

Compunha, incansável, séries de sílabas; com elas e com números, escrevia livros inteiros e tratava por todos os meios de reduzir os princípios da escrita e do cálculo à maior simplicidade e a formas que, com a arte psicológica mais delicada, devem levar lentamente à criança do primeiro passo ao segundo; depois, rápida e firmemente, ao 
terceiro e ao quarto, ainda que sem vazios e sobre a base do segundo perfeitamente apercebido. Mas agora, em vez das letras que em Stanz fazia escrever com giz às crianças, fiz com que desenhassem ângulos, quadrados, linhas e arcos. (Pestalozzi, s/d., p. 37-38).

A experiência de Burgdorf foi interrompida em 1804, mas Pestalozzi deixou como legado a solidificação dos princípios fundamentais de sua pedagogia, apresentados no livro Como Gertrudes ensina seus filhos (1801), composto de 24 cartas sobre a instrução elementar dirigidas a seu amigo Gessner, de Zurich. Trata-se, como aponta Söetard (2010, p. 104), de sua obra mais sistemática, na qual busca responder quais as finalidades e os meios da educação, que saberes e habilidades práticas são necessários à criança e como lhes poderiam ser oferecidos pelo professor ${ }^{3}$. Refletindo sobre suas experiências, Pestalozzi adquiriu a certeza de que, como já haviam afirmado Rousseau (1999, p. 84) e Condillac (Barros, 1971, p. 151159), não se devia raciocinar com as crianças pequenas, mas limitar-se a desenvolver o seu espírito, fixando-se assim nos objetivos de

estender cada vez mais o círculo de sua intuição; [...] imprimir neles as intuições levadas a sua consciência; [...] ministrar-lhes conhecimentos de linguagem suficientes para tudo o que a natureza e a arte haja levado a sua consciência e deva levar ainda (Pestalozzi, s/d., p. 51).

A ideia de ordenação das intuições em séries e de sua convergência ao ponto final, essência do método, ele teria extraído da prática, e já àquela altura confessava ao amigo e correspondente Gessner que "desde há trinta anos não tinha lido livro algum [...] só vivia de minhas convicções, que eram produtos de intuições numerosas"

${ }^{3}$ Neste ensaio, essa obra constitui a principal fonte para a apresentação da filosofia e pedagogia do autor. Para uma análise aprofundada, em português, de um conjunto maior de escritos de Pestalozzi, consultar os trabalhos de Söetard (2010) e Incontri (1996). 
(Pestalozzi, s/d., p. 40), e que desde os vinte anos havia abandonado a filosofia: "para a execução do meu plano, afortunadamente, não necessitei de nenhum aspecto desta filosofia, que me parece tão complexa" (Pestalozzi, s/d., p. 129). Apesar do longo tempo distante dos livros, as marcas do pensamento dos filósofos que leu persistiram, notadamente Kant (Vicenti, 1994, p. 79) - quando Pestalozzi (s/d., p. 117) afirma que só pela educação o homem pode chegar a ser homem - e Rousseau (1999, p. 45-76) - quando trata da natureza humana, das fases do desenvolvimento da criança e do modo de educar seguindo os preceitos naturais em sua ordem correta:

A primeira hora da instrução da criança é a hora de seu nascimento. A natureza a instrui desde o instante em que seus sentidos chegam a ser sensíveis a suas impressões. [...] Toda a instrução do homem não é, pois, outra coisa senão que a arte de auxiliar a este anelo da natureza por seu próprio desenvolvimento, e esta arte descansa fundamentalmente na proporcionalidade e harmonia das impressões que se hão de comunicar à criança com o grau preciso de suas forças desenvolvidas. (Pestalozzi, s/d., p. 42).

Também se encontram presentes em Pestalozzi marcas dos enciclopedistas e do liberalismo da Revolução Francesa, e, não por acaso, a Assembleia Nacional, na mesma época em que tramitava o Relatório e projeto de decreto sobre a organização geral da instrução pública (1792), do Marquês de Condorcet (1743-1794), condecorou Pestalozzi com o título de Cidadão da República Francesa (Söetard, 2010, p. 104). Sua concordância com Condorcet (2008, p. 19-20) se expressa, por exemplo, no desejo de popularizar o saber para que se minimize a dependência e se promova a autonomia dos cidadãos, "ou seja, ministrar em geral o grau de inteligência e capacidade mental que necessitam todos para viver uma vida independente e sábia, para livrar os pobres do risco de serem um joguete da astúcia alheia" (Pestalozzi, s/d., p. 61-62). Como decorrência, defende que os livros de ensino, 
"pedras fundamentais para a instrução humana”, ao lado dos mapas, figuras e demais materiais de ensino deveriam ser abundantemente disseminados, bem divulgados e baratos. A exemplo de Comenius (1592-1670) (1997, p. 361-370), desejava que os livros de ensino se referissem uns aos outros em gradação e que formassem um todo, mesmo que tivessem existência própria e difusão em separado (Pestalozzi, s/d., p. 61-62). Em outras palavras, ainda que por autoindulgência ou por elogio anti-intelectualista, Pestalozzi afirme ter extraído tudo de suas experiências e intuições, ao se examinar o que escreveu, desvela-se que a "prática" jamais se desprende da "teoria", a tal ponto que se possa negar a incidência do que sabe mediante experiência indireta (estudos, leituras) sobre o que faz (ação pedagógica).

Em Iverdon, na Suíça Francesa, Pestalozzi funda, em 1805, o Instituto de Neufchâtel, em que retoma o trabalho educativo e a metodologia já desenvolvida em Burgdorf, criando também uma sistemática de trabalho com os professores pela qual se reuniam duas vezes por semana para discutir e avaliar seus trabalhos (Arce, 2002, p. 68). Para Incontri (1996, p. 26), Iverdon representa a plena realização do que fora o primeiro ensaio do método de Pestalozzi, ocorrido anos antes em Stanz. Essa afamada escola reuniu cerca de 150 pensionistas, tendo atraído alunos e educadores de toda a Europa, dentre os quais Friedrich Fröebel (1782-1852) e J. F. Herbart (1776-1841). A fama europeia de Pestalozzi valer-1he-ia outra condecoração, dessa vez a de “cavaleiro" de Alexandre, czar da Rússia em 1814. Desentendimentos, porém, com os colaboradores minaram a boa condução da escola e tiveram seu ápice com a saída do próprio Pestalozzi, em 1825. Retirado em Neuhof, escreveu, em 1826, dois livros autobiográficos intitulados Eventos da minha vida e, sugestivamente, $O$ canto do cisne. $\mathrm{O}$ pedagogo suíço adoecera, vindo a falecer no início do ano seguinte.

O método de Pestalozzi foi objeto de grande interesse por parte dos reformadores da educação da primeira metade do século XIX, posto que suas ideias combinavam às preocupações sociais afiliadas aos ideais políticos daqueles tempos revolucionários teses 
sobre a cognição da criança e prescrições para a solução de problemas práticos da escola elementar (Ossembach Sauter, 2002, p. 36-37). A esse propósito, parece pertinente a afirmação de Incontri (1996, p. 18) de que Pestalozzi teria representado "a transição, o passo entre o iluminismo francês e o idealismo alemão", manifesta na mencionada condecoração pela Assembleia Nacional Francesa e na adoção de seu método para a reforma da nascente Alemanha. Na Prússia, com efeito, o pensamento de Pestalozzi exerceu importante influência na reforma do sistema educativo, iniciada em 1809 por Wilhem von Humboldt (1767-1835). De acordo com Castro (2002, p. 78-79), nessa época era grande o seu prestígio nos círculos mais próximos do reformador, notadamente entre seus colaboradores, G. H. Nicolovius e J. W. Süvern. Pestalozzi era, além disso, amigo do filósofo J. G. Fichte (1762-1814), ideólogo do novo Estado alemão, que o havia exortado a escrever Minhas investigaçóes sobre o curso da natureza no desenvolvimento da raça bumana (1798), considerado o seu trabalho mais maduro sobre a essência e o destino da humanidade (Söetard, 2010, p. 104).

Humboldt pretendia superar as escolas estamentais existentes em benefício de uma formação geral comum aos cidadãos e, nesse sistema, tinha a escola elementar como a primeira e basal etapa do esforço do Estado de formar um homem consciente de sua dignidade humana e de seu pertencimento a uma comunidade nacional. A diretriz de A. Zeller, a quem coube dirigir o seminário de professores de Königsberg, era pestalozziana, posto que a Humboldt interessava a sua ênfase no "elementar" como cerne e expressão do primeiro nível educativo. Incontri observa, todavia, que na apropriação "idealista" do pensamento de Pestalozzi, tanto a proposta de educação do autor se torna "estatizante", como sua concepção de Deus adquire uma conotação panteísta que, segundo a autora, não estão presentes em sua obra.

Também no Brasil, o método de Pestalozzi pautou uma reforma da instrução pública. Em 1890, no estado de São Paulo, o médico e 
educador Caetano de Campos (1844-1891) a iniciou pela reforma da Escola Normal, pois acreditava que a mudança fundamental residia em uma boa formação dos professores. Assim, ele seguia o mestre de Iverdon, para quem "formar os professores é essencial para que estes sejam um guia suficiente para estar sempre um passo adiante da criança no processo de instrução" (Pestalozzi, s/d., p. 62). Nessa reforma, a Escola Normal teve o seu currículo ampliado e foram criadas as escolas-modelo, tidas tanto como um campo de experimentação dos futuros professores quanto como "centro de irradiação da escola renovada" e do paradigma a ser seguido pelas demais escolas públicas do estado (Souza, 1998, p. 36). Nas escolas-modelo, o ensino intuitivo deveria guiar os procedimentos para o ensino dos saberes elementares. De acordo com a compreensão de Caetano de Campos e dos demais defensores de sua adoção nas escolas públicas paulistas, esse método fundava-se no uso dos sentidos, na observação direta dos objetos e dos fenômenos da natureza e na atividade da criança, e por isso as escolas deveriam ser aparelhadas para que elas pudessem observar, isto é, travar contato direto com objetos oferecidos à percepção, e trabalhar, ou seja, realizar, durante o processo de ensino, atividades similares às que os adultos realizam no mundo do trabalho (Valdemarin, 1998, p. 68-69). Intrigante, talvez pela morte prematura do reformador Caetano de Campos, que no ambiente paulista da república nascente Pestalozzi tenha sido tão falado, mas tão pouco lido: não se registram por essa época livros em português a seu respeito, tampouco traduções de suas obras, das quais nos ressentimos até hoje.

Como não poderia deixar de fazer, sendo ele um pedagogo reformador, Pestalozzi sempre manifestou duras críticas à escola elementar de seu tempo. Ele afirma, por exemplo, que nessa escola "a natureza e a arte estão [...] não só separadas, mas postas em oposição por homens malvados”. (Pestalozzi, s/d., p. 46). Daí que não só as escolas seriam absolutamente ineficientes, como também perniciosas ao desenvolvimento da infância: 
Sua experiência e sua capacidade são já grandes nesta idade (criança de 3 anos); mas nossas escolas antipsicológicas não são em essência senão máquinas artificiais que destroem todos os efeitos da capacidade e da experiência, que a própria natureza nelas criou [...]. Se deixa as crianças gozar plenamente da natureza até os cinco anos; se deixa obrar neles todas as impressões desta [...]. E depois que gozaram cinco anos inteiros desta beatitude da vida sensível, tira-se bruscamente de sua vista toda a natureza que lhes rodeia [...] se lhes acorrenta impiamente durante horas, dias, semanas, meses e anos à contemplação de letras miseráveis, insípidas e uniformes, e atam-nos a uma marcha extenuante de toda a vida, capaz de torná-los loucos se compará-la com seu estado anterior. (Pestalozzi, s/d., p. 44-45).

Sua compaixão pelas crianças, arrastadas a contragosto para as inúteis escolas de seu tempo, o animou a propor um método que as estimulasse e despertasse nelas o interesse e a simpatia pelo saber:

Se pudéssemos testemunhar o indescritível aborrecimento que invade a alma infantil quando se passam, uma após a outra, horas fatigantes se ocupando de coisas que não trazem nenhum estímulo às crianças nem podem lhes parecer de alguma utilidade, e se quiséssemos concordar que esses mesmos fatos ocorreram em nossa infância, jamais nos estranharíamos com a preguiça do aluno que se arrasta para a escola como uma baba. (Pestalozzi, 1996, p. 123).

Pestalozzi insistia na importância dos primeiros anos de vida e na relação entre mãe e filho para o desenvolvimento moral da criança - assunto que expõe minuciosamente em Cartas sobre educação infantil (1819) -, e estabelecia como fundamento da educação intelectual o princípio da intuição. Seu método, contraposto ao verbalismo que abominava, era baseado na experiência direta da criança com o mundo dos objetos, da qual partiria lógica e gradativamente das impressões sensíveis à percepção de suas qualidades fundamentais; o número, a 
forma e a palavra dariam lugar às noções claras e abstratas da aritmética, da geometria e da linguagem. Todo o círculo de conhecimentos que se cria pelos cinco sentidos procede da observação da natureza e da atenção dirigida a recolher e reter tudo o que o conhecimento oferece às crianças.

A educação deveria seguir escrupulosamente as leis da natureza, ou a ordem natural, entendida, em seu método, como as corretas sequência e gradação, no que facilmente se reconhecem os traços da pedagogia humanista de Comenius (1997, p. 165-182), bem como as proposições de Rousseau em Emílio (Rousseau, 1999, p. 90-92). É sobre tal crença que, compreendendo a linguagem como o primeiro meio de conhecimento da espécie humana, ato que "condensa os progressos humanos", ele recomenda unir por completo o ensino à linguagem. Por essa lógica, às crianças só deveria ser ministrado o ensino da leitura depois que aprendessem a falar, de modo que fosse seguido o mesmo caminho que teria levado o selvagem ao homem civilizado: "o selvagem determina primeiro os objetos, depois os nomeia e, por último, os relaciona com os demais. Mais tarde, chega a determinar os estados variáveis do mesmo objeto (ou seja, conforme o tempo e as circunstâncias nas quais se acha)" (Pestalozzi, s/d., p. 5556). Dessa forma, a proposição de que a ontogênese (constituição do ser) repetiria a filogênese (constituição da espécie) tornou-se uma das ideias dominantes do discurso educacional evolucionista desde o final do século XIX.

O conceito, ponto de chegada da educação, é a noção geral do objeto representado, a que se acede pela organização dos sentidos e da inteligência. Ou seja, seria preciso partir das coisas às palavras, inversamente ao ensino "livresco", que parte das palavras às coisas. Pestalozzi recomendava, por exemplo, que os exercícios de cálculo fossem iniciados por meio de objetos reais, mediante os quais os fundamentos fossem assentados e pudessem assegurar os passos ulteriores. Por meio de uma nomenclatura bem graduada e aprendida com solidez, sem subverter a ordem da natureza ou contrariar os 
sentidos da criança, poder-se-ia chegar a estabelecer um fundamento geral para toda a classe de conhecimentos, para que a criança adquirisse conceitos exatos em todos os ramos do saber. Desse princípio deriva a necessidade de o professor proporcionar ao aluno atividades educativas baseadas na observação direta e no uso dos sentidos, que, encadeadas em graus sucessivos de complexidade, permitiriam atingir as noções abstratas de que os conceitos se compõem. A inspiração pestalozziana sustentou, por isso, o uso generalizado de imagens, cartazes, livros ilustrados e a elaboração de todo um campo de ensino baseado na observação, denominado "lições de coisas", que ocupou lugar destacado nos currículos das escolas elementares na transição dos séculos XIX e XX (Ossembach Sauter, 2002, p. 38).

Assim como faz Comenius (1997, p. 207-208) em Didática magna (1621-1657), Pestalozzi defende o método de ensino simultâneo, ao asseverar que o mestre deve instruir muitos alunos de cada vez. Defende a necessidade de o professor simplificar o mecanismo de ensino e aprendizagem, de modo a buscar as formas que excitem mais vivamente a sensibilidade da criança. Além disso, mais importante do que acumular conhecimentos, seria "levantar intensamente as forças do espírito" da criança (Pestalozzi, s/d., p. 55). Isso poderia ser feito por meio da repetição, razão pela qual recomendava que o professor fizesse com que os alunos repetissem seguidamente palavras, definições, frases longas e períodos, que desenhassem livremente ou que traçassem letras na lousa durante os exercícios de repetição. Além disso, deveria estimular os alunos a comunicar uns aos outros o saber que adquiriram.

Recomenda ao educador, além disso, buscar na arte (entendida em sua acepção antiga, mais larga, de técnicas e objetos desenvolvidos pelo homem) meios que pudessem, por sua generalidade e precisão, utilizar para facilitar o conhecimento, criando categorias para associação e classificações para ordenar a massa caótica de representações, ajudando, por fim, sua localização ulterior na memória. $\mathrm{O}$ educador deveria "cortar caminhos para o enriquecimento da 
memória”, utilizando-se de recursos tais como a analogia, a ordem, a atenção e a recitação. Por sua qualidade de reter os conteúdos da experiência, a memória é fundamental para o método de Pestalozzi e, ouso dizer, para qualquer método eficiente de ensino e aprendizagem, sendo surpreendente o fato de ser repelida por muitos educadores.

As críticas à escola não se restringem, entretanto, a seus métodos enfadonhos e ineficazes: Pestalozzi critica as instituições de ensino por seu papel discriminatório, pelo qual se impede que, pelo acesso ao saber, todos os homens atinjam sua plenitude. Em sua alegoria do sistema de ensino, descreve

uma grande casa cujo piso superior brilha por sua arte elevada e completa, mas que só se acha habitada por muitos poucos homens; no médio, vivem mais homens, mas carecem de uma escala com que possam subir de um modo humano ao piso superior, e se manifestam desejos de trepar à maneira de animais, se lhes quebra a perna ou o braço que poderiam utilizar para isto; no terceiro, mora um inumerável rebanho de homens que têm exatamente o mesmo direito que os do superior de desfrutar da luz do sol e do ar são, mas não somente se lhes abandona a si mesmos na obscuridade nauseabunda dos calabouços, como, quando se arriscam tão só a elevar a cabeça para olhar os resplendores do piso superior, se lhes fura brutalmente os olhos. (Pestalozzi, s/d., p. 113).

O princípio "social" de Pestalozzi é fazer com que os homens, por meio da educação, possam bastar-se a si mesmos, ter liberdade e autonomia, pois nada e ninguém os ajudaria. Procura, entretanto, transcender o liberalismo individualista de Condorcet (2008, p. 1821), introduzindo a caridade cristã, ou seja, a ação direta em favor dos desfavorecidos para a superação de sua condição social. Filosoficamente, chega ao igualitarismo ao partir da indagação sobre o ser humano, fundamentando toda a sua filosofia da educação no reconhecimento da existência de uma "natureza humana" incontingente, que pode ser 
buscada e atualizada para a felicidade e a desejável harmonia com o Criador (Incontri, 1996, p. 33-36). Assim como em Comenius, por trás da noção de natureza está a de Deus, e da fé de Pestalozzi em Sua existência e bondade vem a fonte de seus ideais (Incontri, 1996, p. 38). Ele crê que o homem, obra de Deus, "é bom e quer o bem" (Pestalozzi, s/d, p. 116), e que o mal é um desvio da natureza humana (Incontri, 1996, p. 36). Desse modo, assim como não procede "desencantar" a natureza na filosofia educacional pestalozziana, seu método não pode ser dissociado da espiritualidade original e da meta explícita de realização do homem como ser moral, cujas raízes se fixam tanto em Rousseau como em sua orientação religiosa pietista (Incontri, 1996, p. 38). O método e todos os seus componentes não são, para ele, mais do que instrumentos, a fim de que se produza o que não lhe é intrínseco, e que é de uma natureza bastante diferente do mecanismo: a liberdade autônoma do homem.

\section{Referências}

ARCE, Alessandra. A pedagogia na "era das revoluções": uma análise do pensamento de Pestalozzi e Fröebel. Campinas: Autores Associados, 2002.

BARROS, Roque S. M. Condillac e a pedagogia. In: BARROS, Roque S. M. Ensaios sobre educação. São Paulo: Edusp: Grijalbo, 1971.

CASTRO, Federico G. R. Génesis del sistema educativo francês: de la Revolución al Império napoleónico. In: TIANA FERRER, Alejandro; OSSEMBACH SAUTER, Gabriela; SANZ FERNÁNDEZ, Florentino (Coord.). Historia de la Educación (Edad Contemporânea). Madrid: UNED, 2002.

COMENIUS, João Amos. Didática Magna. Trad. Ivone C. Benedetti. São Paulo: Martins Fontes, 1997.

CONDORCET, Jean-Antoine-Nicolas de Caritat Marquis de. Cinco memórias sobre a instrução pública. Tradução e apresentação de Maria das Graças de Souza. São Paulo: Editora Unesp, 2008.

INCONTRI, Dora. Pestalozzi. Educação e ética. São Paulo: Scipione, 1996. (Coleção Pensamento e Ação no Magistério).

OSSEMBACH SAUTER, Gabriela. Génesis de los sistemas educativos nacionales en el mundo occidental. In: TIANA FERRER, Alejandro; OSSEM- 
BACH SAUTER, Gabriela; SANZ FERNÁNDEZ, Florentino (Coord.). Historia de la Educación (Edad Contemporânea). Madrid: UNED, 2002.

PESTALOZZI, Johann H. Cartas sobre educación infantil. 2. ed. Estudio preliminar y traducción de José María Q. Cabanas. Madrid: Technos, 1996. (Colleción Clásicos del Pensamiento).

PESTALOZZI, Johann H. Como enseña Gertrudis a sus hijos. Traducción del alemán de Lorenzo Luzuriaga. Madrid: Édiciones de la Lectura, s/d. (Ciencia y Educación).

ROUSSEAU, Jean-Jacques. Emílio ou Da Educação. Trad. Roberto Leal Ferreira. São Paulo: Martins Fontes, 1999.

SÖETARD, Michel. Johann Pestalozzi. Trad. Martha Aparecida Santana Marcondes, Pedro Marcondes e Ciriello Mazzetto. Recife: Fundação Joaquim Nabuco; Massangana, 2010. (Coleção Educadores).

SOUZA, Rosa F. de. Espaço da educação e da civilização: origens dos grupos escolares no Brasil. In: SOUZA, Rosa F. de et al. O legado educacional do século XIX. Araraquara: Unesp, 1998. p. 20-62.

VALDEMARIN, Vera T. Método intuitivo: os sentidos como janelas e portas que se abrem para um mundo interpretado. In: SOUZA, R.F. de et al. O legado educacional do século XIX. Araraquara: Unesp, 1998, p. 63-105.

VICENTI, Luc. Educação e liberdade: Kant e Fichte. Trad. Élcio Fernandes. São Paulo: Editora da Universidade Estadual Paulista, 1994. (Encyclopaidéia).

WEBER, M. A ética protestante e o espírito do capitalismo. 10. ed. Trad. M. Irene Szmerecsányi e Tamás Szmerecsányi. São Paulo: Pioneira, 1996. 